problems and the underlying mechanisms which can be inferred.

The editors draw attention to the constant risk of unwittingly handicapping an animal through the use of inappropriate testing procedures. The same caution applies to studies of sensory abilities, notably vision and audition, which are described in two further chapters. The account of perceptual processes goes some though much recent experimental work on the perception of social stimuli is omitted. The book also includes contributions on ape language studies, primate evolution, early assessment procedures and influences way towards animating the psychophysics,

on behavioural development, and abnormal behaviour, focusing on the experimental study of depression.

Neither Primate Behavior or Primate Social Relationships is a textbook in the usual sense. But both are aimed at more than research specialists in primatology and should be useful in teaching postgraduates or keen undergraduates. Together they exemplify the new directions in which primatology continues to grow. $\square$

W. C. McGrew is Senior Lecturer in Psychology at the University of Stirling, and J. $R$. Anderson is Maître-Assistant in the Laboratoire de Psychophysiologie, Université Louis Pasteur, Strasbourg.

\section{Keeping pace with biology}

\section{J.T. Bonner}

Elements of Biological Science, 3rd Edn. By William T. Keeton and Carol Hardy McFadden.

W.W. Norton: 1983. Pp.729. \$16.60, £10.95.

Life: The Science of Biology.

By William K. Purves and Gordon $\mathrm{H}$. Orians.

Sinauer/Willard Grant Press/Blackwell Scientific: 1983. Pp.1,182. \$33.75, £19.50.

Biology, 5th Edn.

By John W. Kimball.

Addison-Wesley: 1983. Pp.974.

$\$ 31.95$, £15.95.

Biology, 2nd Edn.

By Donald D. Ritchie and Robert Carola. Addison-Wesley: 1983. Pp.644. \$28.95.

The Biolab Book. By Lundy Pentz. Johns Hopkins University Press: 1983.

Pp.127. \$9.95, £8.50.

EACH year brings new basic biology texts or new editions of established ones. A group from this year's crop is presently sitting on my desk and weighing it down dangerously. The problems of writing a textbook on general biology are quite extraordinary. The successful ones are enormous and encyclopaedic in their coverage; yet despite their appearance of solidity and finality, the subject changes at a reckless pace which forces the need for successively heavier editions. It is true that some books, of which the new edition of Elements of Biological Science by Keeton and McFadden is an example, are specifically designed for a short, one-semester course; but while this book is the third edition of a good, condensed version of the

- Oxford University Press have re-issued in paperback a biography of one of the twentieth century's most notable and controversial biologists, J.B.S. Haldane. The book, simply entitled J.B.S., is by Ronald Clark and first appeared in 1968. Price in paperback is £3.95. highly successful Keeton's Biological Science (for review see Nature 289,$714 ; 1981$ ) it still

Another characteristic of the new books is that they are beautifully illustrated. It is not just that there is an increasing tradition of clear and helpful diagrams and one colour, but also of including stunning photographs. I suspect that the great success of Scientific American and their pioneering of the art form of scientific illustration has done much to influence textbook illustrators.

The authors of general texts have in common one particularly difficult problem: they must satisfy two quite different goals. Some courses are taught from the text, which must be written so that on page one students enter as novices, become progressively informed as they proceed through the book, and on page 1,000 emerge as biological polymaths. Other courses, however, are centred around lectures, the text being used as supplementary reading and as a reference book. In this case continuity is less important than the encyclopaedic qualities and this means special stress in having the facts up-to-date.

The one first-edition book before me is Life: The Science of Biology, by Purves and Orians. While the only way a text can be properly judged is by using it in one's own course, on reading alone this book gets high marks on all the criteria outlined above. It is organized in the conventional way, starting with molecules and ending with populations, and is written in a clear, straightforward manner. Each chapter has a brief but helpful preview and a useful summary at the end which is followed by a short bibliography and a few "study questions". As far as a single mortal could discover, it is up on all the latest, important discoveries. There is perhaps a slightly greater emphasis than usual on evolution and ecology, but the segment covering these topics is excellent. The illustrations are beautiful and the book weighs in at a mere five- and-a-half pounds. It compares favourably with the giants in the field, such as Keeton, and Helena Curtis's Biology, 4th Edn (for review see Nature 302, 166; tips the scales at over four pounds. drawings, sometimes printed in more than
1983), and will no doubt give them stiff competition.

The fifth edition of Kimball's Biology is a good, solid and dependable book (what could be better evidence than the fact that this is the fifth edition?). In this instance the author lays stress on the fact that it has been appropriately modernized, and there is every evidence that the new material has been well integrated.

Ritchie and Carola's Biology, now in its second edition, is less appealing to me, although I can see that others may find it exactly suited to their tastes. It puts special emphasis on issues relating to human beings and in this sense it is less of a general biology text. For instance, development and reproduction are largely centred around ourselves, and human implications are stressed throughout, from genetics to acid rain. It even includes a discussion of $\mathbf{J}$. F. Kennedy's medical problems and a more alarming one on Napoleon Bonaparte's, with the implication that they explain why he fell asleep during the battle of Waterloo. There are some strange omissions. For instance, there is a clear, although brief discussion of how hormones act on cells, but only peptide hormones are described; no mention is made of how steroids are received by target cells.

I have one major complaint against all these books. For reasons I cannot fully control, I tend to examine carefully what a new text has to say about cellular slime moulds. It was most distressing to discover that Purves and Orians, Keeton and McFadden, and Kimball, all say something that is seriously wrong about these glorious beasts. Ritchie and Carola are the only ones that come away clean by not mentioning them at all.

These errors about slime moulds are part of a wider phenomenon that stems from copying what is said in other texts rather than going to original sources. When I first started to teach general biology years ago, many of the books said the largest plant was a brown alga (a kelp) that reached, by some accounts, a length of 1,500 feet. This bit of misinformation goes back into the last century and was repeated endlessly, in some instances into the $1960 \mathrm{~s}$, even though in 1915 T.C.Frye and his co-workers had firmly established the world record was about 150 feet. This is only a slight shift in a decimal point, and eventually the truth will out. Textbooks change mainly by cultural evolution, but in the cases of brown algae and slime moulds there is a closer resemblance to slow genetic evolution.

As an addendum, a word about Pentz's Biolab Book. I am no expert on laboratory manuals, but I must say this one is quite special. It is well written (although the print is hard to read) and has most amusing drawings. I sincerely hope the laboratory exercises are equally good and turn out to be useful.

J.T. Bonner is a Professor in the Department of Biology at Princeton University. 